EstAg 31 (1996) 333-342

\title{
La concepción plotiniana del alma como logos de la inteligencia
}

Según el esquema procesional de Plotino, la Inteligencia produce el Alma, lo mismo que el Uno-Bien produce la Inteligencia. Pero, ¿cómo tiene lugar la procesión del Alma a partir de la Inteligencia? Como el primer principio, la segunda Hipóstasis no produce ni por reflexión, ni por voluntad arbitraria. Si la esencia constitutiva de la Inteligencia consiste en contemplar al Uno-Bien y ser a la vez Inteligencia y multiplicidad de inteligibles, el Alma contempla también a su generador, la Inteligencia, y es además Alma única y multitud infinita de almas. Por tanto, en cierto sentido, el Alma tiene una esencia análoga a la de la Inteligencia, salvo que ésta contempla al Uno-Bien, y el Alma contempla a la Inteligencia.

"El Alma es el logos y el acto de la Inteligencia (hópos voû kai évép$\gamma \in(\alpha)$ lo mismo que la Inteligencia es el logos y el acto del Uno" ${ }^{\text {. ¿Podemos }}$ considerar que la Inteligencia sea el primer logos y el Alma el segundo? Rist no lo cree así ${ }^{2}$ ¿ ¿Cómo el Uno-Bien que está por encima de toda determinación, podría tener su representación en el logos, que contiene precisamente las formas? Para Plotino "la Inteligencia sería el logos del Uno si éste fuera una forma" 3. El Alma es logos de la Inteligencia, su función es expresarla. Ahora bien, la Inteligencia, por su desarrollo y despliegue en una multiplicidad de inteligibles, es también logos del Uno-Bien. Pero mientras que la Inteligencia, que constituye con los inteligibles una unidad perfecta, es un logos inmanente, el Alma es un logos exterior y expansivo.

1. En. V, 1 (10), 6, 44-45. La edición de las Enéadas utilizada es la de Paul HenRY y HansRudolf Schwyzer, Plotini Opera, Oxford, Clarendon Press, 3 vols, 1964-1977. También nos servimos de la excelente traducción española de Jesús IGAL, Plotino. Enéadas I-IV, Madrid, Gredos, 2 vols., 1982 y 1985 . Y hacemos uso además de la ya clásica edición y traducción francesa de Émile BrÉHIER, Plotin. Ennéades, París, Les Belles Lettres, 6 tomos en 7 vols., 19241938 (3ª ed., 1960).

2. Cfr. John M. RIST, Plotinus: the Road to Reality, Cambridge, Cambridge University Press, 1967, p. 84.

3. En. VI, 7 (38), 17, 41-42. 
El movimiento de despliegue es análogo al del logos espermático de los estoicos donde está concentrada la razón del ser. Pero Plotino quiere salvar la transcendencia del logos, y para ello, es necesario que las formas desplegadas no lo sean según un logos inmanente, como en los estoicos, sino según un logos que tenga raíces profundas en la Inteligencia. Tiene que haber un principio inferior que realice su propia actividad 4: la transmisión y el despliegue ordenado de las formas. Este principio inferior tiene su fuente en los inteligibles contenidos en la Inteligencia ${ }^{5}$, y de ahí pasa al Alma para que pueda producir y gobernar el mundo según la razón.

Plotino afirma que el logos es contemplación ${ }^{6}$. Pero, como señala Arnou, hay distintos tipos de contemplación 7 . Una es la contemplación de la razón "contenida en la Inteligencia", otra la de la razón ordenadora, que se encuentra en el Alma, y otra distinta la de la razón engendrada 8, que no posee los dos caracteres propios de la contemplación: visión interior y potencia creadora.

El Alma, en tanto que es logos, es acto. El logos separado del Alma, último principio inteligible, sólo sería un ser irreal. "El Alma es Hipóstasis que procede de la Inteligencia y contemplando la Inteligencia es razón en acto (Ẻvépye la hóyos)"9.

El logos plotiniano es el principio subordinado que, nacido de la Inteligencia ${ }^{10}$, funciona como acto del Alma, en tanto que relaciona lo inteligible con lo sensible, y al transferir las formas inteligibles permite la generación del mundo. Del logos depende la producción y el desarrollo de los seres sensibles.

Este principio de producción y desarrollo está en relación con la "razón seminal" ( $\lambda$ óyos a mepharıkós) de los estoicos, con el Nous de Anaxágoras, en tanto que principio de orden; con el Logos de Heráclito, en tanto que generador de oposiciones y de armonía. "La unidad de la razón viene de los

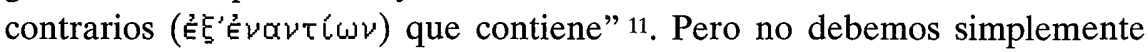
caer en una interpretación ecléctica. Lo que Plotino pretende es remitir al logos las funciones del Demiurgo platónico. No puede admitir un mito inspi-

4. En varias ocasiones pone en conexión évépye la y hó yos. Cfr. Fernand TURLOT, "Le 'logos' chez Plotin”, Les Études philosophiques, 4 (1985), p. 521.

5. Cfr. En. III, 5 (50), 9, 6-7.

6. Cfr. En. III, 8 (30), 3, 3.

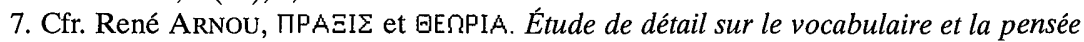
des Ennéades de Plotin, Roma, Presses de l'Université Grégorienne, 1921 (2a ed., 1972), p. 80.

8. Cfr. En. III, 8 (30), 2, 29.

9. En. V, 1 (10), 3, 16.

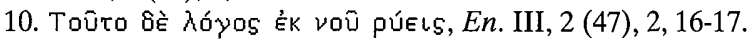

11. En. III, 2 (47), 16, 50. 
rado en un modelo artesanal, porque "las artes son posterior a la naturaleza y al mundo" 12 .

La praxis es siempre inferior a la contemplación, porque implica reflexión, acción mecánica, intermediarios instrumentales. Las razones, actos del Alma, son contemplaciones, y toda contemplación es producción.

\section{La función mediadora del Alma}

El mundo sensible procede de la Inteligencia por la mediación del Alma. La relación del Alma con la Inteligencia es la misma que la de la Inteligencia con el Uno-Bien ${ }^{13}$. De la superabundancia del primer principio procede una energía derivada que, regresando contemplativamente al primer principio, se constituye como segunda Hipóstasis. Esta misma ley de fecundidad que rige la procesión de la Inteligencia a partir del Uno-Bien, exige que después de la Inteligencia haya también una realidad derivada:

Mas el Alma, al mirar a quien es anterior a ella, intelige; pero, al mirarse a sí misma, pone en orden y gobierna al que es posterior a ella, y manda en él. Pues ni siquiera era posible que todas las cosas se detuvieran en la región inteligible cuando era posible que, a continuación, viniera también a la existencia otro que, aunque es inferior, tenía que existir necesariamente, puesto que también existe necesariamente quien es anterior a Él 14 .

El Alma es una imagen ( $E$ ĺḱóv) de la Inteligencia, que se propaga, como un reflejo a su alrededor, como el calor alrededor del fuego ${ }^{15}$. Del mismo modo que el logos expresado, el lenguaje hablado, refleja el pensamiento, el lenguaje interior, el Alma refleja la Inteligencia.

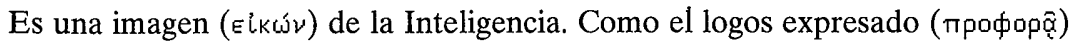
es la imagen del logos interior al Alma, así también ella es el logos de la Inteligencia ( $\lambda$ ó yos voû) y la actividad por la cual la Inteligencia produce la vida para que subsistan los demás seres ${ }^{16}$.

Plotino compara el Uno-Bien con la luz, la Inteligencia, que viene después de él, con el sol, y el Alma con la luna, que recibe la luz del sol ${ }^{17}$. La

12. En. II, 9 (33), 12, 18.

13. Ver nota 1: "El Alma es el logos y el acto de la Inteligencia, lo mismo que la Inteligencia es el logos y el acto del Uno" (En. V, 1 [10], 6, 44-45).

14. En. IV, 8 (6), 3, 26-30.

15. Cfr. En. V, 1 (10), 7, 39-40.

16. En. V, 1 (10), 3, 7-9.

17. Cfr. En. V, 6 (24), 4, 14-16. 
Inteligencia está vuelta hacia el Uno-Bien y contempla dentro de sí misma los inteligibles. Por su parte, el Alma está vuelta hacia la Inteligencia para contemplar los inteligibles, pero ella no los recibe directamente de la fuente, sino sólo una imagen, un reflejo de la luz del sol en la cara de la luna.

El Alma no contempla los inteligibles dentro de sí misma; como en el caso de la segunda Hipóstasis, sino sólo en la Inteligencia. La tercera Hipóstasis, que procede de la Inteligencia, no puede tener su misma perfección, porque lo generado es siempre más imperfecto que lo generante 18. El Alma recibe de la Inteligencia su perfección y alimento, como si fuera un padre que la nutre ${ }^{19}$. Siempre desasosegada e insatisfecha, aspira a un objeto transcendente que le falta y que no encuentra en la Inteligencia.

Plotino compara el Uno-Bien con un centro, la Inteligencia con un círculo inmóvil, y el Alma con un círculo en movimiento, pero movido por el deseo. Mientras el Uno-Bien rodea a su centro directamente, el Alma desea lo que está más allá de la Inteligencia, y la esfera del mundo, impulsada por aquel deseo del Alma, se mueve circularmente ${ }^{20 .}$

Para Bréhier, la metafísica plotiniana se centra en la concepción geocéntrica tomada de Eudoxo. Esta concepción imagina el mundo constituido por esferas concéntricas, la de radio mayor es la de las estrellas fijas, y cada una de las de menor radio lleva un planeta. El mundo así concebido es eterno y se mueve en períodos circulares, que se suceden repitiéndose sin fin 21.

El Alma, contemplando lo que está por encima de ella, es capaz de ordenar el mundo ${ }^{22}$. Sin la mediación del Alma, el mundo sensible no podría producirse. Por esta función ordenadora, el Alma es la intermediaria entre el mundo inteligible y el sensible. Por tanto, al ser intermediaria, el Alma tiene una doble función: 1) es un logos de la Inteligencia, y 2) una Hipóstasis que se constituye regresando contemplativamente a la Inteligencia.

Hipóstasis que se mueve alrededor de la Inteligencia, es la luz ( $\phi \hat{\omega} s$ ) de la Inteligencia y huella ('zuos) que a ella está unida. Porque, por un lado se encuentra unida a la Inteligencia y goza y se sacia de ella, participando, incluso, de la Inteligencia y pensando como ella misma piensa; pero por otro está con lo que viene después de la Inteligencia, o mejor, engendra los seres que, por necesidad, son inferiores a ella 23 .

18. Cfr. En. V, 5 (32), 13, 37-38.

19. Cfr. En. V, 1 (10), 3, 13-15.

20. Cfr. En. IV, 4 (7), 16, 21-30.

21. Cfr. Émile BrÉHIER, La filosofía de Plotino, trad. de Lucía Piossek, Buenos Aires, Sudamericana, 1953, p. 62.

22. Cfr. En. II, 9 (33), 2, 15-18.

23. En. V, $1(10), 7,42-47$. 
El Alma es una huella ('Ł $\chi$ vos) de la Inteligencia, y sólo recibe un reflejo de los inteligibles, pero se trata de un reflejo transparente. Las formas están contenidas en el Alma en un nivel intermedio entre la esencia inteligible y su realización sensible. Las esencias inteligibles son luminosas, sus reflejos en el Alma son transparentes, y sus imágenes sensibles son opacas y sólo se ven por medio del reflejo.

Pues el Alma que pone orden no es un compuesto de materia y forma, sino pura

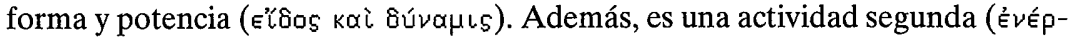

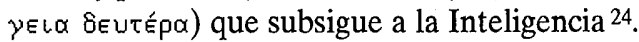

El Alma es la actividad segunda, la Inteligencia es la actividad primera, y el Uno-Bien está más allá de toda actividad. De la plenitud de la Inteligencia procede el Alma, como de la superabundancia del Uno-Bien ha procedido la Inteligencia. El Alma es la tercera y última de las Hipóstasis. Después de ella, el mundo sensible no existe por sí mismo, sino sólo es un reflejo del Alma.

La procesión no supone ninguna intención en el principio. Se trata de un efecto que exterioriza la perfección, o difunde la superabundancia del primer principio. Ahora bien, el mundo sensible no se genera de la perfección o de la superabundancia del Alma, sino, por el contrario, de su defecto, de su indigencia. El Alma contempla los inteligibles en la Inteligencia y no dentro de ella misma. Esta contemplación imperfecta se transforma en deseo de engendrar: como está desasosegada e insatisfecha, porque no puede contener los inteligibles, intenta reproducir su imagen, y esta imagen es el mundo sensible.

Pero, ¿cómo la contemplación imperfecta del Alma se transforma en actividad de producción? El Alma no es fecunda, como el Uno-Bien o la Inteligencia, sino que ha de ser fecundada por la Inteligencia. Engendra el mundo sensible cuando contempla lo inteligible más allá de ella. Para Plotino la acción siempre está subordinada a la contemplación, la actividad de producción surge de la impotencia de la contemplación 25. El Alma se encuentra en un nivel intermedio entre lo inteligible y lo sensible. Los inteligibles, contenidos en la Inteligencia, se reflejan en lo sensible por la mediación del Alma.

El Alma es un intermediario ontológico entre la Inteligencia y el mundo sensible. La segunda Hipóstasis intenta difundir el Bien hasta allí donde incluso parece imposible, hasta la materia ${ }^{26}$.

Plotino distingue dos niveles en el Alma: uno superior que mira a la Inteligencia, y otro inferior que mira al mundo sensible. Así en la Enéada III, 7

24. En. IV, 4 (28), 16, 17-19.

25. Cfr. En. III, 8 (30), 4, 31-36.

26. Cfr. En. IV, 8 (6), 6, 12-14. 
asistimos al descenso del Alma a la Naturaleza en el que se constituye el "tiempo universal". Ahora bien, ¿qué Alma, la superior o la inferior, es el logos de la Inteligencia? Si la parte superior del Alma contempla y crea sin descender, ¿por qué la denomina logos? Si contempla desde la eternidad los inteligibles, ¿cómo la podemos distinguir de la Inteligencia? Lo que distingue a la Inteligencia del Alma superior es su actividad propia que regresa de la multiplicidad de los inteligibles hacia la unidad, y de ahí a la completa identidad de la Inteligencia y lo inteligible, actividad completamente diferente a la del Alma superior que comprende los inteligibles en su multiplicidad regresando contemplativamente a la Inteligencia.

El Alma superior procede de la Inteligencia, sin que ésta sufra ninguna merma. En la procesión del alma también podemos distinguir dos momentos: en el primero es lo indeterminado, como sucedió con la Inteligencia respecto al Uno-Bien, pero lo mismo que la Inteligencia retorna al primer principio, así sucede con el Alma, que regresa a la Inteligencia para contemplar los inteligibles que están contenidos en ella. Pero, al no poder identificarse con ellos, contempla sus imágenes, los contempla como logoi. Este momento de repliegue a la Inteligencia es el que la constituye como Alma, dotándola de logos y haciéndola distinta de la Inteligencia.

El Alma superior, al contemplar los logoi o imágenes de los inteligibles que están contenidos en la Inteligencia, produce el Alma inferior, sin que tampoco haya en esta procesión ninguna pérdida. Esta Alma inferior producida contempla, en primer lugar, la superior, y, en segundo lugar, genera el mundo sensible. El Alma inferior es también un logos de la Inteligencia, pero de carácter inferior al Alma superior, porque contempla los inteligibles a través de las imágenes que la llegan del Alma superior.

En el Alma inferior también hay un momento de repliegue hacia el Alma superior para, contemplándose a sí misma, contemplar las imágenes de los logoi. Por medio de esta autocontemplación recibe las órdenes del Alma superior con las que genera el mundo sensible.

El Alma, que es el logos de la Inteligencia ${ }^{27}$, tiene en Plotino una función demiúrgica. El Alma contempla el modelo inteligible, no en sí misma, sino en la Inteligencia transcendente, y produce el mundo sensible como el Demiurgo del Timeo, pero sin deliberación ni cálculo. Por tanto, el mundo sensible no es fabricado, sino engendrado por una necesidad natural que responde a una

27. El logos no es algo que se posea, es algo que hay que realizar. Dörrie observa aquí una relación estrecha entre Plotino y los estoicos: a pesar de las diferencias, el logos constituye un principio activo, positivo y creador. Cfr. Heinrich DöRRIE, "La doctrine de l'Âme dans le néoplatonisme de Plotin à Proclus", Revue de Théologie et de Philosophie, 23 (1973), p. 118. 
exigencia eterna de la Inteligencia. Pero su producción no podría ser obra de la propia Inteligencia, sino del Alma que procede de la Inteligencia. El mundo sensible es producido porque el Alma contempla la organización ideal en la Inteligencia ${ }^{28}$. La metáfora vitalista de las Enéadas sustituye a la metáfora artificialista del Timeo. Plotino recupera la cosmología vitalista de los estoicos, pero, contra el estoicismo, demuestra la necesidad de recuperar la transcendencia de las Ideas que caracteriza el pensamiento de Platón.

\section{El tiempo como imagen móvil de la eternidad}

En las primeras líneas del tratado "Sobre la eternidad y el tiempo", aparece la siguiente expresión tomada del Timeo platónico: "el tiempo es la imagen de la eternidad" ${ }^{29}$. La estructura del tratado es muy sencilla: consta de una introducción metodológica seguida de dos secciones simétrićas, una dedicada a la eternidad y otra al tiempo, y esta simetría formal, observa Igal, es reflejo de otra más profunda: el tiempo, vida del Alma, es imagen de la eternidad, vida de la Inteligencia 30 .

Plotino comienza exponiendo lo que es la eternidad para intentar conocer lo que es el tiempo. Conocer una realidad como imagen es comprenderla en relación con el modelo de la que es imagen. Para conocer la imagen, por lo tanto, es indispensable conocer el modelo.

Para Plotino la eternidad ( $\alpha i \omega v$ ) es una vida siempre idéntica a sí misma, que excluye la sucesión, el antes y el después, el pasado y el futuro. Una vida tota simul, completamente en el presente, pero un presente que no pasa, un ahora que es siempre ${ }^{31}$.

La eternidad es, pues, esto: lo que ni fue ni será, sino que sólo es, poseyendo este es establemente por el hecho de que ni cambia en el será, ni ha cambiado. Resulta, por tanto, que la vida total, junta y plena y absolutamente inextensa que es inherente al Ser en su ser, eso es precisamente lo que buscamos: la eternidad ${ }^{32}$.

28. Cfr. En. II, 3 (52), 18, 16-17.

29. En. III, 7 (45), 1, 18-21. Cfr. Timeo, $37 \mathrm{~d}$ 5-7.

30. Cfr. Jesús Igal, en Enéadas, vol. II, ed. cit., p. 191.

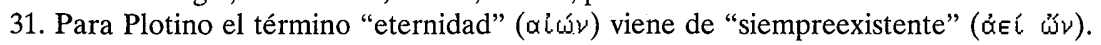
Cfr. En. III, 7 (45), 4, 43. Esta etimología es falsa y se encuentra también en Aristóteles, (De caelo, 279 a $25-28)$.

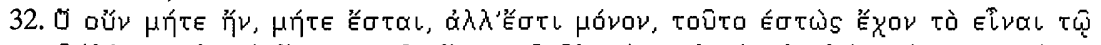

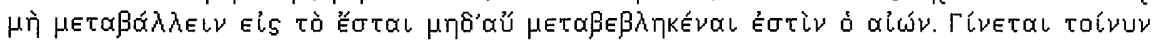

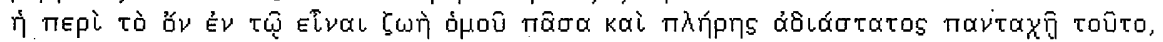

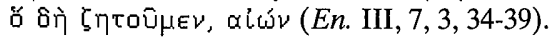


Esta concepción plotiniana de la eternidad es un anticipo de la definición clásica que da Boecio: "Interminabilis vitae tota simul et perfecta possessio" ${ }^{33}$. La eternidad es la vida de la Inteligencia ${ }^{34}$, y su actividad consiste en la contemplación de los inteligibles que contiene en su interior.

El tiempo es a la eternidad lo que el devenir del mundo sensible es al ser inteligible ${ }^{35}$. De lo inteligible se puede decir sólo que es, no que ha sido o que será. Estas determinaciones temporales sólo convienen a los seres del mundo sensible. Platón en el Timeo afirma que el tiempo es "la imagen móvil de la inmóvil eternidad" 36 .

Este carácter cíclico del tiempo es reconocido, de un modo general, por todo el pensamiento antiguo, hasta el punto de que algunos llegan a identificar el tiempo con los movimientos regulares de las órbitas celestes ${ }^{37}$. Pero, observa Plotino, aunque las revoluciones celestes permiten medir el tiempo, no lo originan. El tiempo no es generado $\left(\gamma \in \nu \nu \eta \eta^{\theta} \iota_{5}\right)$ por las revoluciones celestes, sino sólo mostrado, o delatado $(\delta \eta \lambda \omega \theta \in$ ís) por ellas:

Síguese que lo medido -esto es, lo manifestado- por la rotación, será el tiempo; no generado $\left(\gamma \in \nu \nu \eta \theta \in \imath_{\S}\right)$ por la rotación, sino manifestado $\left(\delta \eta \lambda \omega \theta \epsilon \iota_{\varsigma}\right)(\ldots)$. La rotación manifiesta, pues, el tiempo en el que ella misma está, mas el tiempo mismo no debe ya tener algo en que estar 38 .

Plotino critica las teorías que relacionan el tiempo con el movimiento físico, sea como una dimensión intrínseca del mismo, como la distancia o intervalo ( $\delta$ เó $\sigma \tau \eta \mu \alpha)$ que separa su origen y su término ${ }^{39}$, o sea como una determinación extrínseca, como número o medida del movimiento según el antes y el después, que es como lo define Aristóteles ${ }^{40}$. Pero este encadenamiento del antes y el después, esta sucesión de los ahoras, concebido como dimensión del movimiento físico, acaba por identificarse con el desplazamiento espacial que se produce en dicho movimiento, hasta el punto de que ambas líneas (la temporal y la espacial, la línea de ahoras y la línea de puntos) pueden concebirse la una como la medida de la otra.

33. Boecio, De consolatione philosophiae, V, 6 .

34. Cfr. En. III, 5 (50), 12, 21-23.

35. Cfr. En. III, 7 (45), 16, 1-3. Véase Joseph Moreau, Plotin ou la gloire de la philosophie antique, Paris, J. Vrin, 1970, p. 130.

36. Timeo, $37 \mathrm{~d} 5$-7. Cfr. nota 28.

37. Cfr. Aristóteles, Física, IV, 19, 218 a 35 b 5; SAn Agustin, Confesiones, XI, 23, 29.

38. En. III, 7 (45), 12, 50-52 y 13, 1-3.

39. Cfr. En. III, 7 (45), 8, 31.

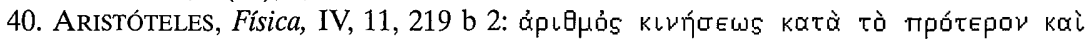
Ǔ́tTepov. 
El tiempo no es una dimensión del movimiento físico, sino una dimensión

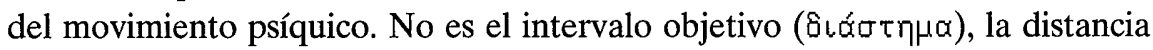

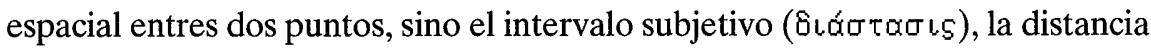
temporal entre una carencia del Alma y una acción que intenta satisfacerla.

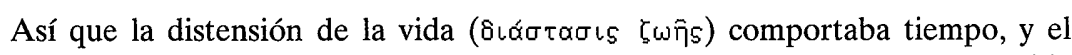
avance incesante de la vida comporta tiempo incesante, y la vida transcurrida comporta tiempo transcurrido 41 .

Plotino anticipa así lo que más tarde San Agustín llamará distentio ani$m i{ }^{42}$. El tiempo ya no es la distancia espacial, sino la distancia psíquica. Si la eternidad es la vida de la Inteligencia, el tiempo es la vida del Alma, vida que es esencialmente sucesiva. Puesto que el Alma, a diferencia de la Inteligencia, no contiene dentro de sí el objeto de su contemplación, los inteligibles, su vida no es, como la de la Inteligencia, posesión total y permanente de sí; sino, por el contrario, desasosiego o insatisfacción que la lleva a buscar fuera de sí lo que le falta en su interior ${ }^{43}$.

Sin embargo, en cierta modo el Alma es eterna, porque procede de la Inteligencia y la contempla. Al intentar imitar la eternidad perfecta de la Inteligencia, produce necesariamente el tiempo, una imagen de la eternidad inferior a sí misma. Por tanto, la producción del Alma es una contemplación disminuida que se despliega en el tiempo.

Para Plotino, como ya hemos visto, si no se conoce la eternidad, no se puede conocer el tiempo. El Alma no sólo se distiende en el tiempo, sino que también se contrae en la contemplación de la eternidad. No sólo se despliega o "procede adelante", sino que también se repliega o se "convierte" hacia la Inteligencia. Pero el regreso contemplativo no se da cronológicamente después de la procesión, puesto que en realidad la procesión es un efecto de la conversión: la producción del tiempo es una imitación debilitada o imperfecta que hace el Alma de la eternidad.

El tiempo procede necesariamente de la eternidad, como una imagen debilitada, de modo que la sucesión homogénea de los ahoras sólo es una imitación de ese ahora total, de esa infinidad en acto, de ese presente absoluto e inmóvil que es la eternidad 44:

41. En. III, 7 (45), 11, 41-43.

42. SAn Agustín, Confesiones, XI, 23, 30. Sobre las relaciones entre la concepción del tiempo en Plotino y San Agustín, véase Jean GurtTon, Le temps et l'éternité chez Plotin et Saint Augustin, París, Boivin, 1933 (2 ed., J. Vrin, 1959).

43. Cfr. En. IV, 4 (28), 16, 26-27. 376-377.

44. Cfr. Silvia FerReTTI, "Eternità e tempo in Plotino", Filosofia (Torino), 44 (1993), pp. 


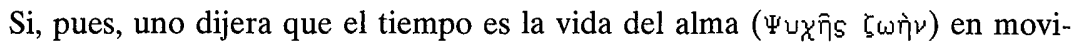
miento de transición de un modo de vida a otro, ¿parecería decir algo con sentido? Sí, porque si la eternidad es vida en reposo, en identidad y en uniformidad e infinitud en acto, y si el tiempo ha de ser una imagen de la eternidad (Eikóvo

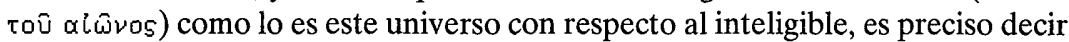
que el tiempo es, en vez de la vida de allá, una vida distinta y como en sentido

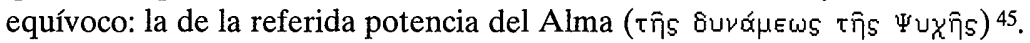

El tiempo imita a la eternidad. Imitar no consiste en hacer una copia idéntica a un modelo, lo que llevaría a la confusión; imitar consiste en producir algo diferente, no un sustituto del modelo, sino un medio de pensar en él. En Plotino podemos distinguir dos tipos de semejanza: el primero es recíproco y se da entre dos realidades que poseen un elemento común; el segundo no requiere que haya un elemento común entre las dos realidades, sino un elemento diferente ${ }^{46}$. El tiempo es semejante a la eternidad de este segundo modo, gracias a la continuidad que no se da en la eternidad donde "todo es a la vez".

Lassègue destaca el privilegio que Plotino concede al futuro entre las instancias temporales ${ }^{47}$. Pero se trata de un privilegio que tiene un valor negativo: "lo que tiene necesidad del futuro sólo puede decirse perfecto por homonimia" 48. Por el contrario, es perfecto lo que posee ya su vida tota simul "sin tener que tomar nada ni del pasado, ni del presente, ni del futuro" 49.

El Alma produce el tiempo. Aunque el tiempo sólo puede darse dentro del Alma, el Alma no se da completamente en el tiempo. El Alma procede de la Inteligencia y, en este sentido, es eterna. Si no participara de la eternidad, no podríamos comprender el tiempo, pues el tiempo sólo se puede comprender con relación a la eternidad. De este modo, el Alma, intermediaria entre lo inteligible y lo sensible, es esencialmente eterna y para producir el mundo sensible engendra el tiempo.

José Ma Zamora CALvo

45. En. III, 7 (45), 11, $43-49$.

46. Cfr. En. I, 2 (19), 2, 9-10.

47. Cfr. Monique Lassègue, "Le temps, image de l'éternité, chez Plotin", Revue philosophique de la France et de l'Étranger, 2 (1982), pp. 405-418.

48. En. III, 7 (45), 6, $42-43$.

49. En. III, 7 (45), 5, 14. 